\title{
Acute pancreatitis induced by acute organophosphate poisoning?
}

\author{
P. G. MOORE \\ M.B. B.S. (Syd.), F.F.A.R.A.C.S.
}

\author{
O. F. JAMES \\ M.S. (Syd.), F.F.A.R.A.C.S., F.F.A.R.C.S., \\ F.F.A.R.C.S.I.
}

Department of Anaesthesia and Intensive Care, The Royal Newcastle Hospital, Newcastle, Australia $23 \notin 0$

\begin{abstract}
Summary
A 32-year-old male with acute organophosphate poisoning developed hyperglycaemia, glycosuria and ketonuria soon after admission to hospital. Serum amylase estimations suggested a diagnosis of acute pancreatitis. He required insulin therapy to control his hyperglycaemia and the organophosphate poisoning was successfully managed by artificial ventilation, an infusion of pralidoxime and intermittent atropine. He was discharged on the 17th hospital day with no permanent physical sequelae.
\end{abstract}

\section{Introduction}

The clinical manifestations and pharmacological management of acute organophosphate poisoning have been previously well described (Grob, 1956; Namba et al., 1971; Vale and Scott, 1974). However, this case report describes an unusual complication of acute organophosphate poisoning which contradicts the expected biochemical response.

\section{Case report}

A 32-year-old male accountant presented to the Emergency Ward of the Royal Newcastle Hospital after becoming ill at his place of employment. He had reported to his medical officer at work approximately $\mathbf{3 0}$ min before, complaining of nausea, dizziness and abdominal cramps. During transport to hospital he became unconscious and developed generalized convulsions. The admitting resident medical officer administered intranasal oxygen and injected the following agents i.v.: diazepam $20 \mathrm{mg}$; phenytoin sodium $250 \mathrm{mg}$; clonazepam $1 \mathrm{mg}$; and dextrose $2.5 \mathrm{~g}$. Because of slow ( $3 \mathrm{breaths} / \mathrm{min}$ ) and inadequate respiration, artificial ventilation was commenced via an oral endotracheal tube. Arterial blood gas analysis before this showed a $\mathrm{PaO}_{2}$ $80 \mathrm{mmHg}, \mathrm{PaCO}_{2} 106 \mathrm{mmHg}, p \mathrm{H} \mathrm{6.913}$, base excess $-15 \mathrm{mg} / \mathrm{l}$.

Clinical examination following intubation revealed the following physical signs: systemic arterial BP (initially $90 / 50 \mathrm{mmHg}$ ) decreased to $50 /-\mathrm{mmHg}$ after positive pressure ventilation; heart rate 48 beats $/ \mathrm{m}$. profuse sweating, hypersalivation, rhinorrhoed, bronchorrhoea and lacrimation; incontinence ब의 urine and faeces.

Neurological examination showed the followigg signs: an unconscious patient unresponsive to oll stimuli; generalized flaccid paralysis and areflexiä; fine muscular fasciculations; pinpoint unreactiæe pupils; absent oculocephalic and caloric reflexes.

With these clinical findings and the past history of chronic endogenous depression a provisional diagnosis of self-administered organophosphate posabing was made. Blood was collected for serum cholinesterase assay, full blood count, serum electro仿es and liver function tests.

He was treated with atropine $0.6 \mathrm{mg}$ i.v. with $\sum_{\text {an }}$ immediate increase in pulse rate to 90 beats $/ \mathrm{min}$ a $\overline{\text { Bd }}$ $\mathrm{BP}$ to $135 / 65 \mathrm{mmHg}$. Pralidoxime 1 g. i.v. was give्gn and resulted in reduction in secretions from the noș, oropharynx, trachea and skin, spontaneous small movements of hands and feet and some returim, though diminished, of tendon reflexes. He remained unconscious, unresponsive and without spontaneous respiratory efforts. When stabilized he was trasferred to the Intensive Care Unit (ICU).

The finding of an empty bottle of coumaphos the patient's locker at work the day following ady mission confirmed the provisional diagnosis. The ingested dose of coumaphos (0,0-diethyl-0-3-chloro4-methyl-2-oxo-2 $H$-1-benzopyran-7-yl phosphorothioate) was estimated to be $14 \mathrm{~g}$. The calculated $\mathrm{LD}_{50}$ for this man who weighed $85 \mathrm{~kg}$ was $1 \cdot 275 \cong \mathrm{g}$ $(15 \mathrm{mg} / \mathrm{kg})$.

\section{Investigations}

After admission to the ICU, ward urine test showeed heavy glycosuria and moderate ketonuria. Blo glucose level at that time was $15 \mathrm{mmol} / \mathrm{l}$ (nornal limit, $<8.9 \mathrm{mmol} / 1$ non-fasting state) but wब్s $29.8 \mathrm{mmol} / \mathrm{l}$ when reviewed $90 \mathrm{~min}$ later. Serum cholinesterase concentration was $60 \mathrm{u} . / 1$ (norm range $3000-6000$ u.l). 
Serum amylase concentration $3.5 \mathrm{hr}$ after admission was $1397 \mathrm{u} . / 1$ (normal range 70-300 u./l). This decreased to $301 \mathrm{u} . / \mathrm{l}$ when re-examined $20 \mathrm{hr}$ after admission.

\section{Treatment and progress}

Soluble insulin $20 \mathrm{u}$. subcutaneously was given after the blood glucose was found to be $29.8 \mathrm{mmol} / \mathrm{l}$ and using a 'sliding scale' of soluble insulin a further $16 \mathrm{u}$. of soluble insulin was given in divided doses over the next $12 \mathrm{hr}$. Twenty hr after admission the blood glucose was $10.6 \mathrm{mmol} / \mathrm{l}$. No further insulin was needed and thereafter the blood glucose stayed within normal limits and the urine remained free of sugar.

An infusion of phenytoin sodium $125 \mathrm{mg} / \mathrm{hr}$ maintained to control convulsions was discontinued $16 \mathrm{hr}$ after admission. Diazepam in $5 \mathrm{mg}$ i.v. injections was used to control muscle fasciculations in the first $24 \mathrm{hr}$.

Pralidoxime was given by infusion of $6 \mathrm{~g} / 24 \mathrm{hr}$ for 12 days. Atropine $0 \cdot 6 \mathrm{mg}$ was given by i.m. injection every $6 \mathrm{hr}$ and additional atropine $9.6 \mathrm{mg}$ was given by i.v. injection when the pulse rate fell below 70 beats/min. Atropine was needed for 8 days.

Continuous cardiac monitoring was employed and he needed artificial ventilation for a total of 6 days. By the 2 nd hospital day he exhibited occasional slight spontaneous movements and responded to painful stimuli. On the 3 rd day he responded to verbal commands and could move all limbs. Spontaneous shallow respiratory efforts had returned and he had a weak cough. He was then managed by intermittent mandatory ventilation which was gradually reduced over the next 3 days

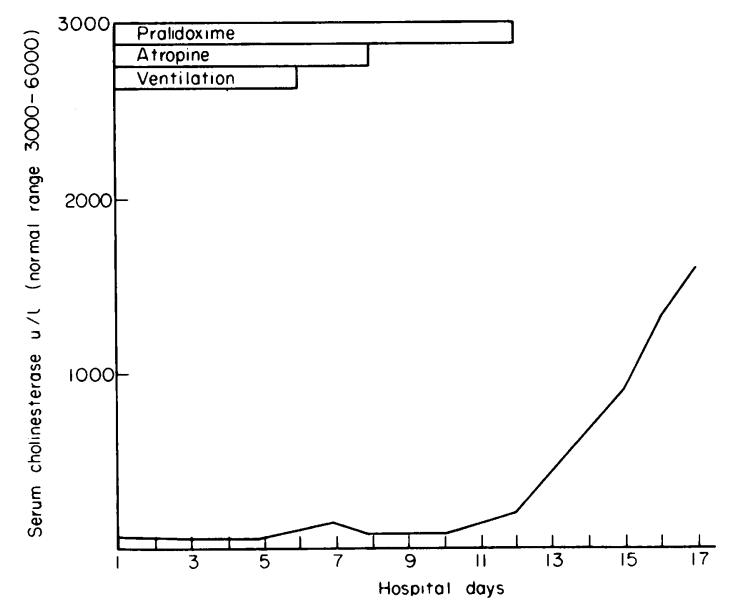

FIG. 1. 32-year-old male with acute organophosphate poisoning. Serial serum cholinesterase concentrations (day 1, $60 \mathrm{u} .1$; day 17,1531 u.l). Time course of main therapeutic measures shown at top of figure. as adequate respirations returned. He gradually gained muscle strength but when his orotracheal tube was removed on the 6th day he had persisting proximal muscle weakness. His physical signs continued to improve and on the 17th day after admission he was discharged from the ICU for in-patient psychiatric care. At this time he had recovered muscle strength but complained of a 'dizzy' feeling and was occasionally incontinent of urine. His serial serum cholinesterase concentrations are shown in Fig. 1.

\section{Discussion}

The clinical effects of the anticholinesterase drugs are almost entirely due to the inhibition of acetylcholinesterase (AChE) whose physiological substrate is acetylcholine (ACh) (Namba et al., 1971). The organophosphate esters act by the formation of a stable acylated enzyme. This results in inactivation of AChE and the accumulation of large amounts of $\mathrm{ACh}$ at the cholinoceptive receptors. The resulting widespread effects can be conveniently separated into 4 main areas: potentiation of postganglionic parasympathetic (muscarinic) activity; persistent depolarization of skeletal muscle; initial stimulation of cells in the central nervous system followed by depression; variable autonomic ganglionic stimulation or blockade.

Management of this patient followed accepted principles (Vale and Scott, 1974) and included the use of atropine to alleviate the muscarinic and central nervous system manifestations of organophosphate poisoning, pralidoxime to improve the force of muscular contraction and artificial ventilation to maintain adequate gas exchange.

Organophosphate poisoning should also cause predictable biochemical effects as the autonomic nervous system, which is modified by organophosphate, plays an important role in the regulation of insulin secretion. Stimulation of the vagus nerve (Kaneto, Kosaka and Nakao, 1967; Frohman, Ezdinli and Gavid, 1967) or the administration of parasympathomimetic agents (Malaisse et al., 1967; Kaneto et al., 1968) are both known to stimulate insulin secretion. Also vagotomy (Frohman et al., 1967) or cholinergic blockade (Permutt, Keller and Santiago, 1977) are known to inhibit insulin secretion (Permutt et al., 1977). Therefore, the expected response to organophosphate would be stimulation of insulin secretion and a reduction in the blood glucose concentration. This is supported in the report of a case of temporary remission of diabetes mellitus in a patient following organophosphate poisoning (Samantray, 1978).

The occurrence of hyperglycaemia, glycosuria and ketonuria in the subject of this report is therefore paradoxical. The use of i.v. glucose on admission 
would have raised the blood glucose concentration temporarily but would not be sufficient to produce persistent hyperglycaemia. Also although anticholinergic agents are known to increase the blood glucose concentration in the normal patient this would not seem to be important in this patient in view of the severity of the poisoning and the degree of muscarinic stimulation present. The finding of a raised serum amylase may provide the explanation for this patient's hyperglycaemia. This finding suggests that the patient may have developed an episode of acute pancreatitis which was mild and self-limiting. The clinical signs of such a process would have been masked by the overwhelming clinical manifestations of the organophosphate poisoning. The reasons why this patient might develop acute pancreatitis are unclear although the occurrence of severe circulatory collapse present in the initial phase of this patient's poisoning is a possible explanation. Local effect of the organophosphate may also be a possibility. However, the finding of a raised serum amylase may not necessarily prove the diagnosis of acute pancreatitis (Takahashi et al., 1980). From theoretical analysis one would expect an increase in exocrine secretion of the pancreas and salivary glands in response to the increased muscarinic activity caused by the organophosphate. Whether this causes an abnormal increase in serum amylase is unknown. Thus the cause of the patient's metabolic and pancreatic response to the organophosphate poisoning remains unproved.

\section{References}

Frohman, L.A., Ezdinli, E.Z. \& Gavid, R. (1967) Effectgf vagotomy and vagal stimulation on insulin secretioe. Diabetes, 16, 443.

Grob, D. (1956) The manifestations and treatment $\frac{\mathrm{O}}{\mathrm{df}}$ poisoning due to nerve gas and other organic phosphame anticholinesterase compounds. Archives of Interngl Medicine, 98, 221.

Kaneto, A., Kajinuma, H., Kosaka, K. \& NakaO, K. (1968) Stimulation of insulin secretion by parasympathomimetie agents. Endocrinology, 83, 651 .

Kaneto, A., Kosaka, K. \& Nakao, K. (1967) Effects stimulation of the vagus nerve on insulin secretion. Endocrinology, 80, 530.

Malaisse, W., Malaisse-lagae, F., Wright, P.H. \& ASHMORE, J. (1967) Effects of adrenergic and cholinergid agents upon insulin secretion in vitro. Endocrinology, 8 975.

Namba, T., Nolte, C.T., Jackrel, J. \& Grob, D. (19ך) Poisoning due to organophosphate insecticides. Americ\& Journal of Medicine, 50, 475.

Permutt, M.A., Keller, D. \& Santiago, J. (1977) Chol 유ergic blockade in reactive hypoglycemia. Diabetes, 26 , 121.

SamaNTRAY, S.K. (1978) Organophosphorous poisoning a remission of diabetes. Medical Journal of Australia, 1, 445 .

Takahashi, M., Maemura, K., Sawada, Y., Yoshioka, $q$. \& SuRimoto, T. (1980) Hyperamylasemia in critigati injured patients. Journal of Trauma, 20, 951.

VALE, J.A. \& SCOTT, G.W. (1974) Organophosph앙uㅗ poisoning. Guy's Hospital Reports, 123, 13. 